\title{
Properties of Poly(ethylene terephthalate)/Layered Silicate Nanocomposites Prepared by Two-Step Polymerization Procedure
}

\author{
Yusuke IMAI, ${ }^{\dagger}$ Yoshinari INUKAI, and Hiroshi TATEYAMA \\ Institute for Structural and Engineering Materials, National Institute of Advanced Industrial Science \\ and Technology (AIST), 807-1, Shuku-machi, Tosu, Saga 841-0052, Japan
}

(Received July 30, 2002; Accepted January 10, 2003)

\begin{abstract}
Intercalated nanocomposites of poly(ethylene terephthalate) (PET) and layered silicate (ME) were prepared by a two-step polymerization process: a melt polymerization of bis(2-hydroxyethyl)terephthalate and a subsequent solid-state polymerization. Two kinds of cationic surfactants, dodecyltriphenylphosphonium bromide $\left(\mathrm{C}_{12} \mathrm{TP}\right)$ and 10 [3,5-bis(methoxycarbonyl)phenoxy]decyltriphenylphosphonium bromide (IP10TP) were employed as compatibilizers. The dispersibility of ME in PET was investigated by X-Ray diffraction analysis and optical polarization microscopy. The thermal and dynamic mechanical behavior of the nanocomposites was compared with that of pure PET and a PET/ME composite. By utilizing IP10TP as the compatibilizer, better dispersion of ME into the PET matrix could be achieved. The obtained PET/IP10TP/ME nanocomposite showed a higher tensile storage modulus compared with those of pure $\mathrm{PET}, \mathrm{PET} / \mathrm{ME}$, and $\mathrm{PET} / \mathrm{C}_{12} \mathrm{TP} / \mathrm{ME}$, especially in the temperature range above the glass transition temperature.

KEY WORDS Nanocomposites / Poly(ethylene terephthalate) / Layered Silicates / Compatibilizer /

Dynamic Mechanical Property /
\end{abstract}

Much attention has been paid to polymer/layered silicate nanocomposites because remarkable improvements can be expected in mechanical, thermal, and physicochemical properties over their base polymers or conventional composites. ${ }^{1-4}$ Development of poly(ethylene terephthalate) (PET)/layered silicate nanocomposites is highly desired because of their practical importance. ${ }^{5-7}$ We have recently reported the preparation of PET/expandable fluorine mica (ME) nanocomposites via an in-situ polymerization method utilizing a novel reactive compatibilizer, 10-[3,5-bis(methoxycarbonyl)phenoxy]decyltriphenylphosphonium bromide (IP10TP, Scheme 1). ${ }^{8}$ The obtained nanocomposites showed a high flexural modulus compared with that of pure PET. However, the molecular weight of PET in the nanocomposites was found to be low for practical applications, probably due to the high viscosity during the melt polymerization. A solid-state polymerization (SSP) process can be applied to increase the average molecular weight of PET without being affected by the viscosity of the reactants. $^{9-11}$ In the SSP process, the crystallized PET prepolymer is heated at a temperature below the crystalline melting point $\left(T_{\mathrm{m}}\right)$ but well-above the glass transition temperature $\left(T_{\mathrm{g}}\right)$ under a flow of inert gas or under vacuum. The hydroxyethyl end groups of the PET prepolymer are considered to be concentrated into the amorphous region during the crystallization process. The transesterification reaction between the chain ends leads to the high-molecular-weight PET.

In the present study, we applied the SSP process to prepare PET/IP10TP/ME nanocomposites with a suitable molecular weight. A PET/ME composite with dodecyltriphenylphosphonium bromide $\left(\mathrm{C}_{12} \mathrm{TP}\right.$, Scheme 1) was prepared in order to determine the effect of the functional groups of IP10TP on the final properties of the PET nanocomposites. Pure PET and a PET/ME composite without any compatibilizing agent

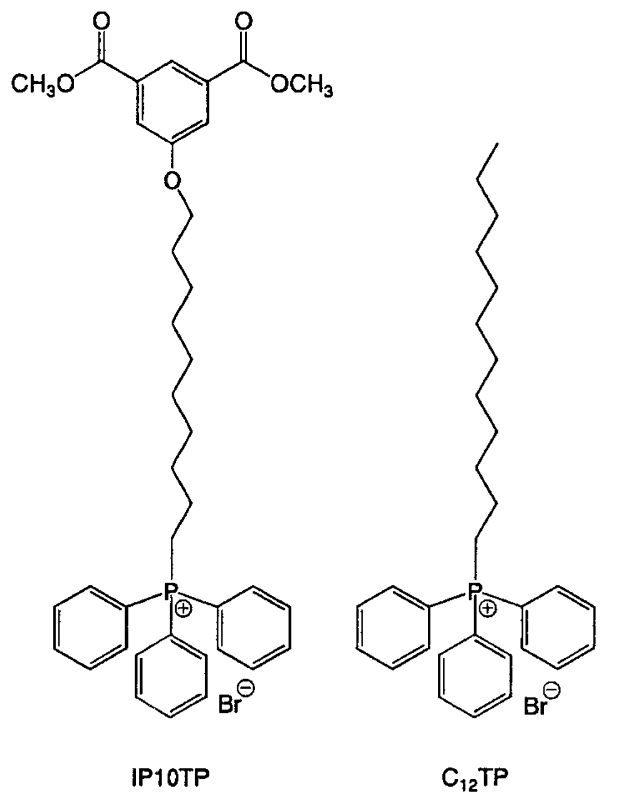

Scheme 1.

${ }^{\dagger}$ To whom correspondence should be addressed (Tel: +81-942-81-3648, Fax: +81-942-81-3693, E-mail: y-imai@aist.go.jp). 
were also prepared via the same process for comparison. The dispersibility of $\mathrm{ME}$ in the PET matrix and the thermal and dynamic mechanical properties of PET/IP10TP/ME nanocomposites were compared with those of the pure PET, PET/ME, and PET/ $\mathrm{C}_{12} \mathrm{TP} / \mathrm{ME}$.

\section{EXPERIMENTAL}

\section{Characterization Methods}

X-Ray diffraction (XRD) measurements were carried out on a Philips APD X'Pert diffractometer. The $\mathrm{XRD}$ data were collected using $\mathrm{Cu}-K_{\alpha}$ radiation between 1 and $10^{\circ}$ in $2 \theta$ at a step of $0.05^{\circ}$. The observations by a polarization microscope were carried out at $280^{\circ} \mathrm{C}$ under cross nicol condition. Thermogravimetric analysis (TGA) was performed on a Rigaku Thermal Analysis System TAS200 TG8101D at a heating rate of $10^{\circ} \mathrm{C} \mathrm{min}^{-1}$ up to $800{ }^{\circ} \mathrm{C}$ under flowing air at $100 \mathrm{~mL} \mathrm{~min}^{-1}$. Gel permeation chromatographic analysis (GPC) was carried out on a Tosoh HLC-8220GPC (TSKgel SuperHM-M column $\times 2$ ) by using $10 \mathrm{mM}$ sodium trifluoroacetate in $1,1,1,3,3,3-$ hexafluoroisopropanol as an eluent after calibration with standard poly(methyl methacrylate). Two mg samples were dissolved in $1 \mathrm{~mL}$ of the eluent, and the insoluble part including the layered silicates was removed by centrifugation at $6,000 \mathrm{rpm}$ for $10 \mathrm{~min}$. The supernatants were filtered with a PTFE membrane filter (pore size $0.2 \mu \mathrm{m}$ ) and subjected to the measurement. Differential scanning calorimetry (DSC) analysis was performed on a DSC6200 (Seiko Instruments, Inc.) under a nitrogen atmosphere at a heating or cooling rate of $10{ }^{\circ} \mathrm{C} \mathrm{min}^{-1}$. About $10 \mathrm{mg}$ samples sealed in aluminum pans were melted at $300^{\circ} \mathrm{C}$ for $1 \mathrm{~min}$, then quenched by liquid nitrogen, and used to determine glass transition $\left(T_{\mathrm{g}}\right)$, melting $\left(T_{\mathrm{m}}\right)$, and crystallization $\left(T_{\mathrm{c}}\right)$ temperatures. To determine the degree of crystallinity $\left(\chi_{\mathrm{c}}\right)$, the samples were crystallized at $140^{\circ} \mathrm{C}$ for $2 \mathrm{~h}$ before measurement. Dynamic mechanical analysis (DMA) was conducted on a DMS6100 (Seiko Instruments, Inc.) in a tensile mode at a frequency of $2 \mathrm{~Hz}$ with a heating rate of $2{ }^{\circ} \mathrm{C} \mathrm{min}^{-1}$ from $-120^{\circ} \mathrm{C}$ to $220^{\circ} \mathrm{C}$. Samples for DMA were prepared by injection molding into a $50 \times 5 \times 2.5 \mathrm{~mm}$ shape and crystallized at $140^{\circ} \mathrm{C}$ for $2 \mathrm{~h}$ before measurement.

\section{Materials}

Bis(2-hydroxyethyl)terephthalate (BHET) was purchased from Tokyo Kasei Kogyo, Japan. Antimony(III) trioxide was supplied from Katayama Chemical, Japan. Dodecyltriphenylphosphonium bromide $\left(\mathrm{C}_{12} \mathrm{TP}\right)$ was synthesized by reacting equimolar amounts of 1bromododecane and triphenylphosphine (both from
WAKO Chemicals, Japan) at $110^{\circ} \mathrm{C}$, followed by recrystallization from acetone-hexane. 10-[3,5Bis(methoxycarbonyl)phenoxy]decyltriphenylphosphonium bromide (IP10TP) was prepared as reported in a previous study. ${ }^{8}$ The layered silicate employed in this study was expandable fluorine mica (ME) with a two-dimensional size of $6 \mu \mathrm{m}$ and a cation exchange capacity of $1.2 \mathrm{mmol} \mathrm{g}^{-1} .^{12}$ This material is commercially available as SOMASIF ME-100 from CO-OP Chemical, Co., Ltd., Japan.

\section{Preparation of Intercalation Compound from $C_{12} T P$ and $M E$}

Eight grams of ME was mixed with $92 \mathrm{~g}$ of deionized water for $2 \mathrm{~min}$ in a blender to obtain a uniform gel of ME and water. Then $25 \mathrm{~g}$ of the ME gel (containing $2.0 \mathrm{~g}$ of $\mathrm{ME}$ ) and $177 \mathrm{~g}$ of deionized water were mixed and stirred at room temperature for $1 \mathrm{~h}$ to obtain a $1 \mathrm{wt} \%$ dispersion of ME in water. $\mathrm{C}_{12} \mathrm{TP}(1.23 \mathrm{~g}$, $2.4 \mathrm{mmol}$ ) was dissolved in $200 \mathrm{~g}$ of deionized water, and to the solution was added the $1 \mathrm{wt} \%$ aqueous dispersion of ME. The resulting suspension was stirred at room temperature for at least $48 \mathrm{~h}$. The suspension was filtered, washed well with deionized water, and dried in vacuo. The amount of adsorbed compatibilizer estimated by TGA was $1.13 \mathrm{mmol} \mathrm{g}^{-1}$-ME.

\section{Preparation of Intercalation Compound from IP10TP and $M E$}

The preparative method was almost the same as above, but IP10TP was dissolved in a methanol-water mixture (106 and $200 \mathrm{~g}$, respectively). The amount of adsorbed compatibilizer estimated by TGA was $1.13 \mathrm{mmol} \mathrm{g}^{-1}$-ME.

\section{Preparation of Nanocomposites}

A mixture of BHET ( $40 \mathrm{~g})$, intercalation compound (1.6 g equivalent of $\mathrm{ME})$, and $\mathrm{Sb}_{2} \mathrm{O}_{3}(11.5 \mathrm{mg}$, $0.025 \mathrm{~mol} \%$ to BHET) was heated at $185^{\circ} \mathrm{C}$ for $10 \mathrm{~min}$ under a nitrogen atmosphere. The temperature was then gradually increased and the pressure was progressively reduced to polymerize BHET. The generated ethylene glycol was trapped with liquid nitrogen. When the temperature reached $275^{\circ} \mathrm{C}$ and the pressure became less than 0.1 torr, the polymerization was continued for time $t_{\mathrm{m}}$ (Table I) under these conditions. The resulting meltpolymerized product was cooled with liquid nitrogen, milled into a size of about $1 \mathrm{~mm}$, and crystallized at $140^{\circ} \mathrm{C}$ for $2 \mathrm{~h}$. Solid-state polymerization was carried out by heating the melt-polymerized product at $240^{\circ} \mathrm{C}$ under nitrogen flow $\left(0.5 \mathrm{~L} \mathrm{~min}^{-1}\right)$ for time $t_{\mathrm{S}}$ (Table I). Pure PET and a PET/ME composite were prepared in the same way as the control samples. 
Table I. Sample compositions and results of polymerization

\begin{tabular}{|c|c|c|c|c|c|c|c|}
\hline sample code & composition & compatibilizer & $\mathrm{ME}(\mathrm{wt} \%)^{\mathrm{a}}$ & $t_{\mathrm{m}}(\mathrm{h})^{\mathrm{b}}$ & $t_{\mathrm{s}}(\mathrm{h})^{\mathrm{c}}$ & $M_{\mathrm{n}}\left(\mathrm{g} \mathrm{mol}^{-1}\right)$ & $M_{\mathrm{w}} / M_{\mathrm{n}}$ \\
\hline IP-1 & PET/IP10TP/ME & $\begin{array}{l}\text { IP10TP } \\
1.13 \mathrm{mmol} \mathrm{g}^{-1}-\mathrm{ME}\end{array}$ & 3.6 & 0.5 & - & 5300 & 1.74 \\
\hline IP-2 & & & & 3 & - & 6300 & 2.61 \\
\hline IP-3 & & & & 0.5 & 5 & 11600 & 2.56 \\
\hline$\overline{\mathrm{PET}}-\overline{1}-$ & $\overline{\mathrm{PET}}-\overline{-}$ & none & $\overline{0}-$ & $\overline{1}$ & - & $4 \overline{600}-$ & $\overline{1.69}-$ \\
\hline PET-2 & & & & 1 & 0.5 & 10000 & 2.05 \\
\hline PET-3 & & & & 1 & 2 & 13200 & 1.93 \\
\hline$\overline{M E}-\overline{1}$ & $\overline{\mathrm{PET}} \overline{\mathrm{M}} \overline{\mathrm{ME}}$ & none & $\overline{3} . \overline{9}$ & 1 & - & $3 \overline{500}$ & $\overline{1} . \overline{67}$ \\
\hline ME-2 & & & & 1 & 0.5 & 7700 & 1.99 \\
\hline ME-3 & & & & 1 & 2 & 11100 & 1.74 \\
\hline $\mathrm{C}-1$ & $\mathrm{PET} / \mathrm{C}_{12} \mathrm{TP} / \mathrm{ME}$ & $\begin{array}{l}\mathrm{C}_{12} \mathrm{TP} \\
1.13 \mathrm{mmol} \mathrm{g}^{-1}-\mathrm{ME}\end{array}$ & 3.5 & 1 & - & 5900 & 1.89 \\
\hline $\mathrm{C}-2$ & & & & 1 & 1 & 8300 & 1.93 \\
\hline $\mathrm{C}-3$ & & & & 1 & 2 & 10300 & 2.10 \\
\hline
\end{tabular}

${ }^{\mathrm{a}} \mathrm{ME}$ content in composites determined by TGA. ${ }^{\mathrm{b}}$ Reaction time at $275^{\circ} \mathrm{C}$ and $<0.1$ torr in melt polymerization process. ${ }^{c}$ Reaction time at $240{ }^{\circ} \mathrm{C}$ under $\mathrm{N}_{2}$ flow $\left(0.5 \mathrm{~L} \mathrm{~min}^{-1}\right)$ in solid state polymerization process.

\section{RESULTS AND DISCUSSION}

\section{Melt Polymerization and Solid-State Polymerization}

Table I summarizes the compositions of the samples prepared in this study and the results of polymerization. In the case of the melt polymerization of PET/IP10TP/ME, the number average molecular weight $\left(M_{\mathrm{n}}\right)$ was 5300 for the melt polymerization time $t_{\mathrm{m}}=30 \mathrm{~min}$ (IP-1). Even after $t_{\mathrm{m}}=3 \mathrm{~h}$ (IP-2), $M_{\mathrm{n}}$ did not increase very much. This implies that it is difficult to obtain high-molecular-weight PET nanocomposites by the melt polymerization process when IP10TP is utilized as the compatibilizer. The SSP process was then carried out with the melt-polymerized precursors. The precursors were heated at $140^{\circ} \mathrm{C}$ for $2 \mathrm{~h}$ prior to the SSP process for the following purposes. ${ }^{9-11}$ The water molecule remaining in the sample would cause degradation of PET during the reaction, so the samples must be dried vigorously. Moreover, by the crystallization of PET during the heating process, the reactive chain ends and catalysts are considered to be concentrated into the amorphous region, which is necessary for the progress of SSP. The fusion of the precursor particles during the SSP process can also be avoided. If the amorphous precursors are directly subjected to the SSP, the fusion takes place, and this will cause a reduction of the reaction rate of the SSP due to the reduced surface area. After the SSP of PET/IP10TP/ME with the reaction time $t_{\mathrm{s}}=5 \mathrm{~h}$, the $M_{\mathrm{n}}$ increased from 5300 to 11600 (IP-3). The SSP progressed successfully for the PET/IP10TP/ME nanocomposite.

The other samples were prepared in the same scheme. The melt polymerization time $t_{\mathrm{m}}$ was set to $1 \mathrm{~h}$ to prepare the melt-polymerized products with almost equivalent molecular weights to IP-1. Their $M_{\mathrm{n}}$ values were 4600 (PET-1), 3500 (ME-1), and 5900 (C-1), respectively. These were applied for the SSP. By the SSP with $t_{\mathrm{s}}=2 \mathrm{~h}$, the $M_{\mathrm{n}}$ values of pure PET, PET/ME, and $\mathrm{PET} / \mathrm{C}_{12} \mathrm{TP} / \mathrm{ME}$ increased to 13200 (PET-3), 11100 (ME-3), and 10300 (C-3), respectively, which were almost identical to that of IP-3. In the following section, the dispersibility of ME and the thermal and dynamic mechanical properties of PET/IP10TP/ME (IP-3) were compared with those of pure PET (PET-3), PET/ME (ME-3), and PET/C ${ }_{12} \mathrm{TP} / \mathrm{ME}$ (C-3). These samples have almost the same molecular weights.

\section{Dispersibility of ME in PET Matrix}

Figure 1 shows the XRD patterns of the dried ME, intercalation compounds, and the corresponding composites. In the PET/ME composite (Figure 1a), the 001 reflection peak was observed at $1.33 \mathrm{~nm}$, while a small peak still remained at $0.96 \mathrm{~nm}$, which corresponded to the 001 reflection of the dried ME. The increase in the basal spacing from 0.96 to $1.33 \mathrm{~nm}$ means that the PET chain can intercalate into the interlayer region of unmodified $\mathrm{ME}$ to some extent. On the contrary, basal spacings of ME in PET/ $\mathrm{C}_{12} \mathrm{TP} / \mathrm{ME}$ (Figure 1b) and PET/IP10TP/ME (Figure 1c) composites were found to decrease from those of corresponding intercalation compounds $(2.45 \mathrm{~nm}$ and $3.33 \mathrm{~nm}$, respectively). It is considered to be due to the change of packing or orientation of compatibilizers in the interlayer region during the polymerization. The basal spacings of $\mathrm{ME}$ in PET/C $12 \mathrm{TP} / \mathrm{ME}$ and PET/IP10TP/ME, appeared at 1.82 and $1.86 \mathrm{~nm}$, respectively, are larger than that in $\mathrm{PET} / \mathrm{ME}$.

If the 001 reflection peaks of the three composites are compared, that in PET/IP10TP/ME composite is obvi- 
ously broader than the other two peaks. This difference reflects the average number of regularly stacked silicate layers $\left(N_{\mathrm{s}}\right)$ in PET matrix. $N_{\mathrm{s}}$ can be considered as a kind of index of the dispersibility of ME and estimated as follows. The size of the regularly stacked ME crystallites can be estimated using Scherrer's formula (eq1), ${ }^{13}$

$$
D_{001}=0.9 \lambda / \beta \cos \theta
$$

where $D_{001}$ is the size of the crystallite, $\lambda$ is the wavelength $(0.1542 \mathrm{~nm}), \beta$ is the full width at half maximum of the 001 reflection peak in radians, and $\theta$ is Bragg's angle. $N_{\mathrm{s}}$ was then calculated by dividing $D_{001}$ by the basal spacing. The results are summarized in Table II. It is clear that the utilization of IP10TP results in a better dispersion of ME. On the contrary, the utilization of $\mathrm{C}_{12} \mathrm{TP}$ resulted in little change in the dispersibility of

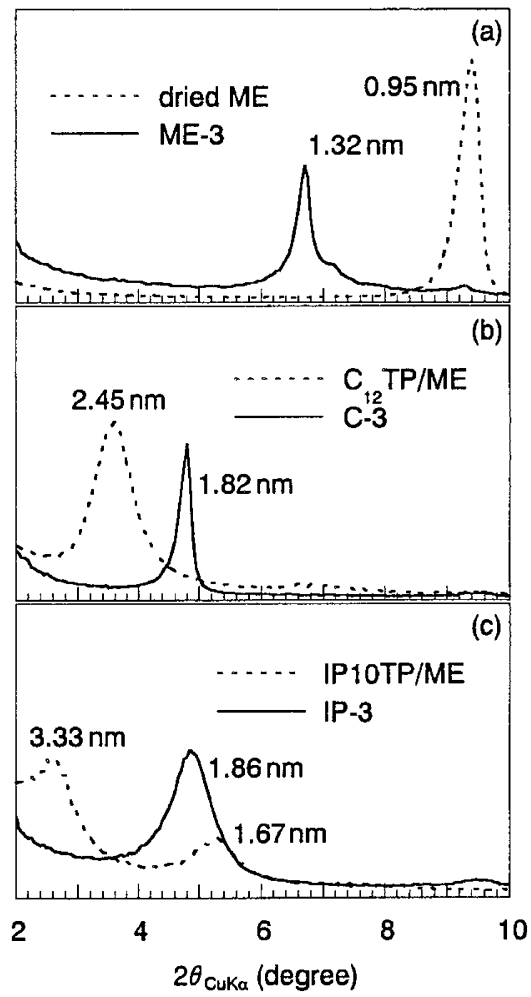

Figure 1. X-Ray diffraction patterns for (a) dried ME and PET/ME (ME-3); (b) $\mathrm{C}_{12} \mathrm{TP} / \mathrm{ME}$ intercalation compound and $\mathrm{PET} / \mathrm{C}_{12} \mathrm{TP} / \mathrm{ME}$ (C-3); (c) IP10TP/ME intercalation compound and PET/IP10TP/ME (IP-3).
ME compared to the uncompatibilized PET/ME.

The dispersibility of ME was further confirmed by observation with polarization microscopy (Figure 2). In
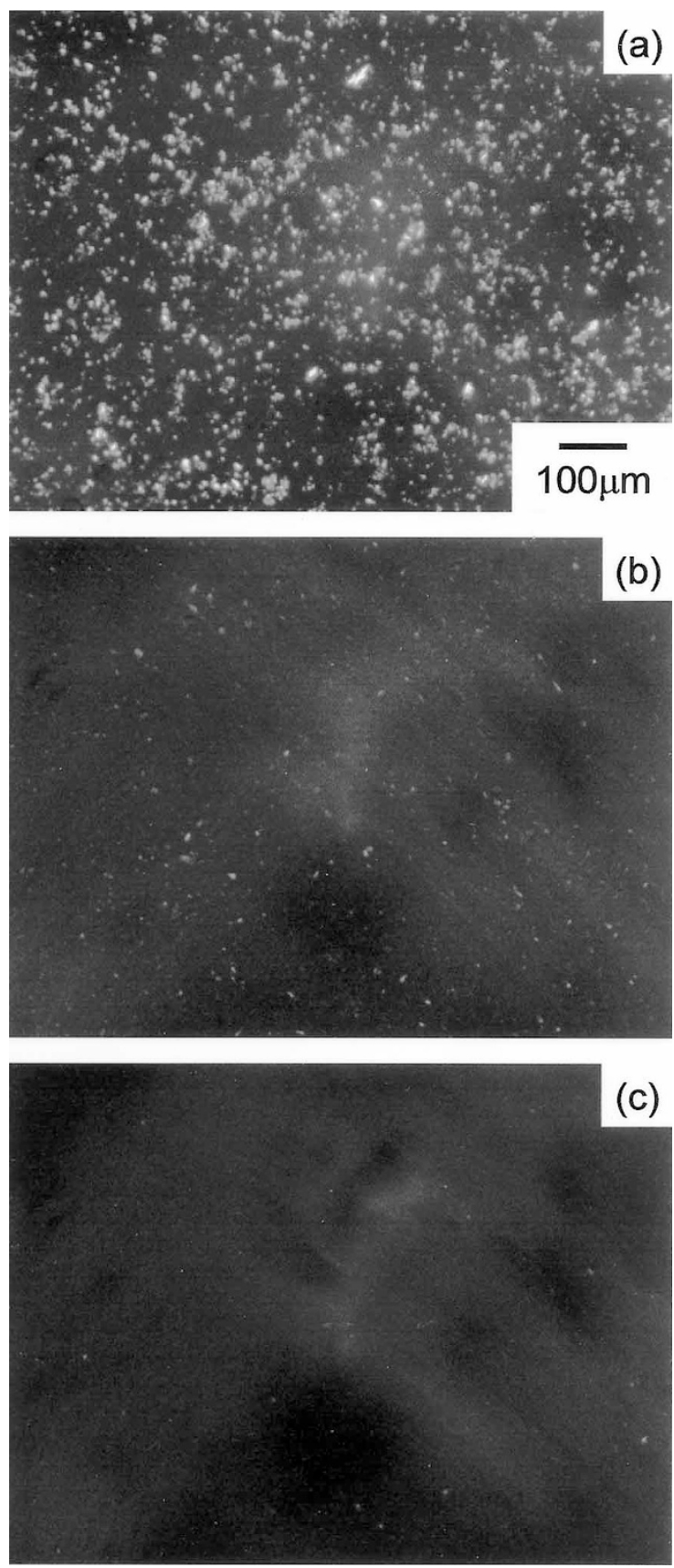

Figure 2. Images observed using a polarization microscope: (a) PET/ME (ME-3); (b) $\mathrm{PET} / \mathrm{C}_{12} \mathrm{TP} / \mathrm{ME}$ (C-3); (c) PET/IP10TP/ME (IP-3).

Table II. Results of X-Ray diffraction analysis

\begin{tabular}{llccc}
\hline sample code & composition & basal spacing $(\mathrm{nm})$ & $D_{001}(\mathrm{~nm})^{\mathrm{a}}$ & $N_{\mathrm{s}}^{\mathrm{b}}$ \\
\hline PET-3 & PET & - & - & - \\
ME-3 & PET/ME & 1.33 & 28.2 & 21.2 \\
C-3 & PET/C 12 TP/ME & 1.82 & 37.5 & 20.6 \\
IP-3 & PET/IP10TP/ME & 1.86 & 9.4 & 5.1 \\
\hline
\end{tabular}

${ }^{\mathrm{a} C r y s t a l l i t e}$ size of ME estimated from the full width at half maximum for the 001 reflection peak of ME using Scherrer's formula. ${ }^{13}$ b The average number of regularly stacked silicate layers. 
Table III. DSC results of solid state polymerized samples

\begin{tabular}{llcccc}
\hline sample code & composition & $T_{\mathrm{g}}\left({ }^{\circ} \mathrm{C}\right)^{\mathrm{a}}$ & $T_{\mathrm{m}}\left({ }^{\circ} \mathrm{C}\right)^{\mathrm{a}}$ & $T_{\mathrm{c}}\left({ }^{\circ} \mathrm{C}\right)^{\mathrm{b}}$ & $\chi_{\mathrm{c}}(\%)^{\mathrm{c}}$ \\
\hline PET-3 & PET & 80.5 & 259 & 207 & 40.7 \\
ME-3 & PET/ME & 79.2 & 259 & 220 & 44.6 \\
$\mathrm{C}-3$ & PET/C 12 TP/ME & 79.2 & 258 & 214 & 35.5 \\
IP-3 & PET/IP10TP/ME & 78.1 & 255 & 201 & 36.7 \\
\hline
\end{tabular}

${ }^{\mathrm{a}} \mathrm{DSC}$ heating scan $\left(10^{\circ} \mathrm{C} \mathrm{min}^{-1}\right)$ of melt-quenched samples. ${ }^{\mathrm{b}} \mathrm{DSC}$ cooling scan $\left(10^{\circ} \mathrm{C} \mathrm{min}^{-1}\right)$ of melt-quenched samples. ${ }^{\mathrm{c}}$ The degree of crystallinity estimated by considering the melting enthalpy of $100 \%$ crystalline PET as $117.6 \mathrm{~J} \mathrm{~g}^{-1} \cdot{ }^{14}$ DSC heating scan $\left(10^{\circ} \mathrm{C} \mathrm{min}^{-1}\right)$ of crytallized $\left(140^{\circ} \mathrm{C}, 2 \mathrm{~h}\right)$ samples.

the PET/ME composite (Figure 2a), many particles of layered silicates were observed as bright spots in sizes from a few to several tens of micrometers. The size of the ME crystallites in the PET/ME composite was estimated to be about $30 \mathrm{~nm}$ (Table II). This result indicates that ME crystallites aggregate to form much larger clusters in PET/ME composite. The number and size of such large clusters decreased in PET/ $\mathrm{C}_{12} \mathrm{TP} / \mathrm{ME}$ (Figure $2 b$ ), but the aggregation of ME crystallites is still observed to a certain degree. On the other hand, in the case of PET/IP10TP/ME (Figure 2c), the aggregation of ME crystallites was hardly observed. ME crystallites were dispersed into the range of nanometers. These results indicate that the dispersion of ME is enhanced by the utilization of IP10TP.

\section{Thermal Properties}

The results of DSC analyses are summarized in Table III. The $T_{\mathrm{g}}$ and $T_{\mathrm{m}}$ of PET/IP10TP/ME were found to be slightly lower than those of the other samples. Further, the $T_{\mathrm{c}}$ of PET/IP10TP/ME was even lower than that of pure PET, while those of PET/ME and $\mathrm{PET} / \mathrm{C}_{12} \mathrm{TP} / \mathrm{ME}$ were higher than that of pure PET. In spite of the efficient dispersion of the layered silicates in PET/IP10TP/ME, these results suggest that the utilization of IP10TP prevents the crystallization of PET in the nanocomposite. One possible origin of this effect is the isophthalate moiety of IP10TP. Incorporation of a meta-connection into the PET chain would cause reduction of both the crystallinity and also the $T_{\mathrm{g}} .{ }^{16}$

\section{Dynamic Mechanical Properties}

The temperature dependence of the tensile storage modulus $\left(E^{\prime}\right)$ is shown in Figure 3a, and the ratios of $E^{\prime}$ of the composites to that of the pure PET are plotted in Figure 3b. All three composites exhibited higher $E^{\prime}$ values than that of pure PET, while the enhancement appeared in different magnitudes depending both on the composition and the temperature regions. Below the $T_{\mathrm{g}}$, the value of $E^{\prime}$ of PET/IP10TP/ME was about $25 \%$ higher than that of pure PET. The increase in $E^{\prime}$ of $\mathrm{PET} / \mathrm{C}_{12} \mathrm{TP} / \mathrm{ME}$ was almost the same as that of

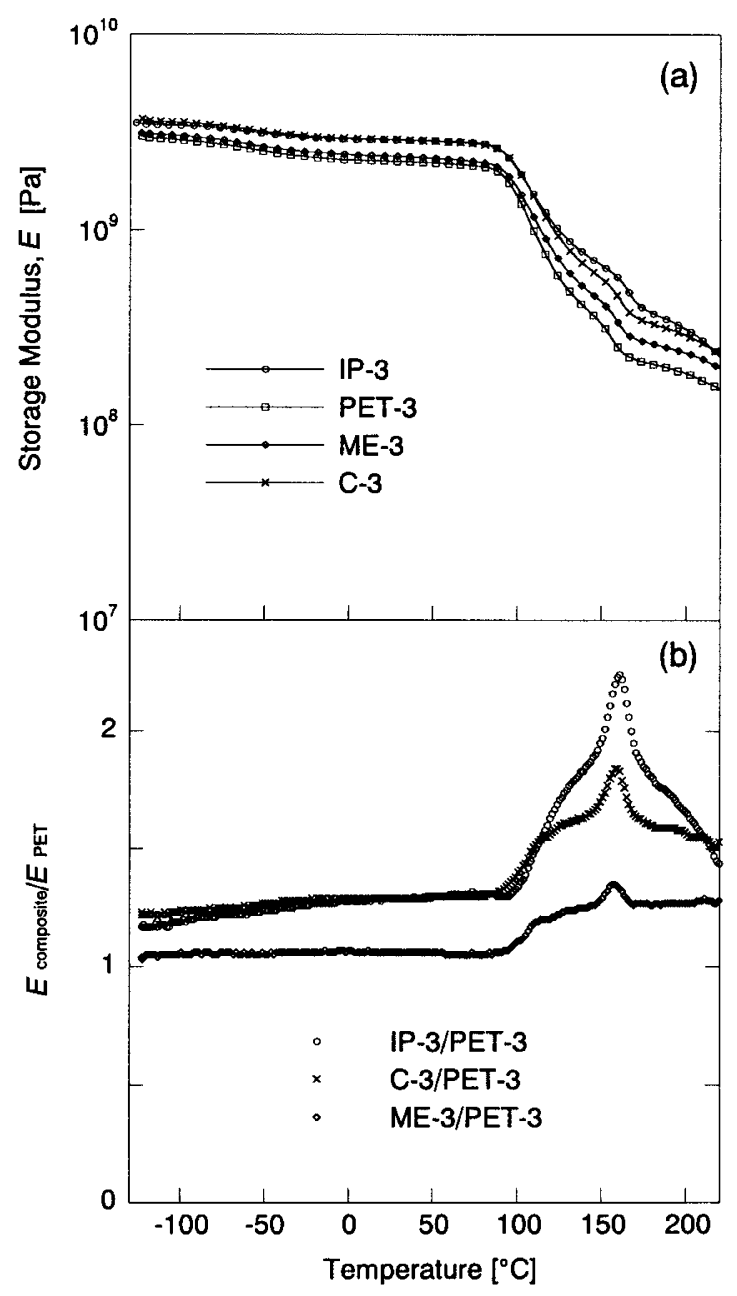

Figure 3. (a) Temperature dependence of tensile storage modulus $\left(E^{\prime}\right)$ for IP-3 $(\bigcirc)$, PET-3 $(\square)$, ME-3 $(\diamond)$, and C-3 $(\times)$. (b) The ratios of $E^{\prime}$ of the composites to that of pure PET.

PET/IP10TP/ME. PET/ME had a lower $E^{\prime}$ than these two, that is, about $5 \%$ higher than that of pure PET. Above the $T_{\mathrm{g}}$, the reinforcement effect of the layered silicate appeared more significantly, ${ }^{15}$ and also the differences between IP10TP and $\mathrm{C}_{12} \mathrm{TP}$ became clear. The ratio of $E^{\prime}$ for PET/IP10TP/ME to that for pure PET increased dramatically with increasing temperature and reached $225 \%$ at $160^{\circ} \mathrm{C}$. In the case of $\mathrm{PET} / \mathrm{C}_{12} \mathrm{TP} / \mathrm{ME}$, the increase in $E^{\prime}$ was about $80 \%$ compared to that of pure PET at maximum. This significant improvement 


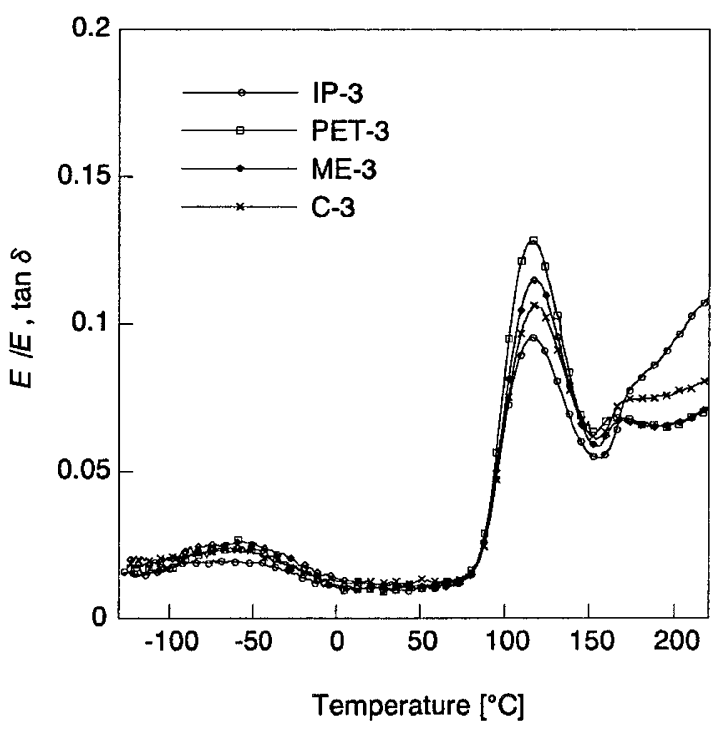

Figure 4. Temperature dependence of $\tan \delta\left(E^{\prime \prime} / E^{\prime}\right)$ for IP-3 $(\bigcirc), \operatorname{PET}-3(\square), \operatorname{ME}-3(\diamond)$, and C-3 $(\times)$.

in the $E^{\prime}$ of PET/IP10TP/ME supports the better dispersion of ME in the PET/IP10TP/ME nanocomposite.

Figure 4 exhibits the changes in loss tangent $(\tan \delta)$. The addition of ME decreased the intensity of the $\alpha$ relaxation peak around $120^{\circ} \mathrm{C}$. This effect was more enhanced in PET/IP10TP/ME as compared with the other two composites, indicating that the movement of the PET chains is more restricted in PET/IP10TP/ME. It is considered that the larger part of the PET chains attaches to the layered silicates due to the better dispersion of ME in the PET/IP10TP/ME nanocomposite. In the higher temperature region, there is a noticeable increase in the $\tan \delta$ value for PET/IP10TP/ME. The same behavior can be observed for $\mathrm{PET} / \mathrm{C}_{12} \mathrm{TP} / \mathrm{ME}$, while the magnitude is rather small compared with that of PET/IP10TP/ME. These peaks can be attributed to the motion in the interface region between the PET matrix and ME. ${ }^{17}$ The larger interface area for PET/IP10TP/ME can explain the larger enhancement of the loss component.

\section{CONCLUSIONS}

High-molecular-weight PET nanocomposites were successfully prepared through the SSP process. Better dispersion of ME in the PET matrix could be achieved by the utilization of IP10TP as the compatibilizer. From the DSC study, IP10TP was found to have an inhibiting effect on the crystallization. The PET/IP10TP/ME nanocomposite showed a higher tensile storage modulus compared with those of the pure PET, PET/ME, and $\mathrm{PET} / \mathrm{C}_{12} \mathrm{TP} / \mathrm{ME}$, especially in the temperature region above the glass transition.

Acknowledgment. This work was supported in part by the Special Coordination Funds for Promoting Science and Technology (Fluidity Promoting Research System) from the Ministry of Education, Culture, Sports, Science and Technology, Japan.

\section{REFERENCES}

1. T. J. Pinnavaia and G. W. Beall, Ed., "Polymer-Clay Nanocomposites," John Wiley \& Sons Ltd., Chichester, 2000.

2. E. P. Giannelis, Adv. Mater, 8, 29 (1996).

3. M. Alexandre and P. Dubois, Mater. Sci. Eng. R., 28, 1 (2000).

4. M. Biswas and S. S. Ray, Adv. Polym. Sci., 155, 167 (2001).

5. Y. Ke, C. Long, and Z. Qi, J. Appl. Polym. Sci., 71, 1139 (1999).

6. T.-Y. Tsai, J. Appl. Polym. Sci., 71, 173 (1999).

7. T.-Y. Tsai, C.-L. Hwang, and S.-Y. Lee, SPE-ANTEC Proc., 248, 2412 (2000).

8. Y. Imai, S. Nishimura, E. Abe, H. Tateyama, A. Abiko, A. Yamaguchi, T. Aoyama, and H. Taguchi, Chem. Mater, 14, 477 (2002).

9. D. Wu, F. Chen, R. Li, and Y. Shi, Macromolecules, 30, 6737 (1997).

10. F. J. Medellin-Rodrigues, R. Lopez-Guillen, and M. A. Waldo-Mendoza, J. Appl. Polym. Sci., 75, 78 (2000).

11. X.-Q. Wang and D.-C. Deng, J. Appl. Polym. Sci., 83, 3133 (2002).

12. H. Tateyama, S. Nishimura, K, Tsunematsu, K. Jinnai, Y. Adachi, and M. Kimura, Clays Clay Miner, 40, 180 (1992).

13. H. P. Klug and L. E. Alexander, Ed., "X-ray Diffraction Procedures for Polycrystalline and Amorphous Materials," John Wiley \& Sons Inc., New York, N.Y., 1954, chap. 9.

14. G. Groeninckx, H. Reynaers, H. Berghmans, and G. Smets, $J$. Polym. Sci., Part B: Polym. Phys., 18, 1311 (1980).

15. S. S. Ray, P. Maiti, M. Okamoto, K. Yamada, and K. Ueda, Macromolecules, 35, 3104 (2002).

16. G. P. Karayannidis, I. D. Sideridou, D. N. Zamboulis, D. N. Bikiaris, and A. J. Sakalis, J. Appl. Polym. Sci., 78, 200 (2000).

17. G. Tsagaropoulos and A. Eisenberg, Macromolecules, 28, 6067 (1995). 